\title{
BEHAVIOR OF THE SLAVE-MAKING ANT, HARPAGOXENUS AMERICANUS (EMERY), AND ITS HOST SPECIES UNDER "SEMINATURAL" LABORATORY CONDITIONS (HYMENOPTERA: FOR MICIDAE)'
}

\author{
By Thomas M. Alloway \\ AND \\ Maria Guadalupe Del Rio Pesado \\ Erindale College \\ University of Toronto \\ Mississauga, Ontario L5L.1C6 \\ Canada
}

\section{INTRODUCTION}

Slave-making ants are social parasites that raid the nests of hostspecies colonies, capture brood, and transport it back to the parasite colony. There, host-species workers eclosing from captured brood become "slaves" which perform all the usual worker-ant functions in the slave-maker colony (see review by Buschinger et al. 1980).

Harpagoxenus americanus (Emery) is an obligatory slave-making parasite which forms mixed colonies with workers of three Leptothorax host species: L. ambiguus Emery, L. curvispinosus Mayr, and $L$. longispinosus Roger. Young $H$. americanus queens found colonies by entering host-species nests, killing or driving off the adults, and inducing the host-species workers which subsequently mature from worker pupae in the nest to rear a brood of slavemaker workers (Wesson 1939). These parasite workers then augment the slave worker force by raiding other host-species nests.

Wesson (1939) and Alloway (1979) observed H. americanus slave raids in the laboratory by placing populous $H$. americanus nests in

\footnotetext{
'This research was supported by a grant from the Natural Sciences and Engineering Research Council (Canada) to the first author and by a scholarship from CONACYT (Consejo Nacional de Ciencia y Tecnologia, Mexico) to the second author. The authors would like to thank Victor Chudin for his assistance in collecting the data and Robin Stuart, David Gibo, and James Beckwith for their constructive comments on the manuscript.

Manuscript received by the editor September 30, 1983.
} 
experimental arenas containing an arbitrarily selected host-species target nest. Under these circumstances, $H$. americanus raids begin when one or more slave-maker workers leave the parasite nest to explore the arena. Whenever such a "scout" discovers the entrance to the target nest, it returns to its own nest and recruits a raiding party. After dispersing the adult residents of the target nest, the raiders carry the captured brood back to the slave-maker nest (Alloway 1979).

Recently, it was discovered that $H$. americanus, $L$ ambiguus, $L$. longispinosus and probably $L$. curvispinosus form facultatively polydomous colonies (Alloway et al. 1982; Del Rio Pesado \& Alloway 1983). Colonies of the three host species are also facultatively polygynous (Alloway et al. 1982). However, H. americanus colonies apparently never contain more than one inseminated egg-laying queen (Buschinger \& Alloway 1977).

In the present paper, we augment previous findings by presenting behavioral observations of $\boldsymbol{H}$. americanus and its slaves interacting with ants from other $H$. americanus colonies and from unenslaved host-species colonies. These observations supplement previous findings for three reasons:

1. The interactions observed were among ants from colonies collected adjacent to one another in nature.

2. The ants were observed for several weeks.

3. Ants from small and "weak", as well as populous and "strong", $H$. americanus and host-species colonies were observed.

\section{Materials and Methods}

Nests of $H$. americanus, L. ambiguus, and L. longispinosus were collected on the Erindale Campus of the University of Toronto, in Mississauga, Ontario. Since we wanted to observe the behavior of ants from parasite nests occurring close together in nature, we looked for places where there were at least two $H$. americanus nests within less than $2 \mathrm{~m}$ of each other. Whenever such a spot was found, we laid out a $2 \mathrm{~m}$ by $2 \mathrm{~m}$ quadrant centering on the parasite nests and then collected, numbered, and mapped the location of all $H$. americanus and host-species nests in the quadrant. Altogether, 19 quand rants were collected; but two pairs of adjacent quadrants were combined to permit observation of large groups of $H$. americanus 
nests. See Del Rio Pesado (1983) for a complete demographic description of the colonies studied.

In the laboratory, the ants were removed from their natural nests, established in artificial nests (Alloway 1979), and censused. Then they were transported to a naturally lighted, unairconditioned room, where the field maps were used to reconstruct among the artificial nests the same spatial relations as had existed among the natural nests. In addition to these "natural" quadrants, we also observed one control quadrant containing two $H$. americanus nests from different collection sites. In some cases, individual ants were marked. See Del Rio Pesado and Alloway (1983) for a detailed description of these procedures.

Ad libitum behavioral observations were made $8 \mathrm{~h}$ a day, 5 days a week during June, July, and August. Five quadrants were observed in 1980; and 14 quadrants were observed in 1981. An assistant was employed during 1981 to permit more detailed behavioral observations.

\section{RESUlts}

\section{Raiding}

The slave-makers raided or attempted to raid the nests of adjacent colonies. Most raided nests belonged to unparasitized L. ambiguus and L. longispinosus colonies. However, in the control quadrant and in the two "natural" quadrants containing more than one $H$. americanus colony, the slave-makers from one colony raided nests belonging to another parasite colony.

Alloway (1979) observed that the raiding behavior of $H$. americanus is not highly stereotyped even when ants from a single parasite nest are interacting with ants from a single target nest. In the present study in which the slave-makers were often interacting with ants from several naturally adjacent colonies, the results were so complex and variable that their complete presentation requires a separate description of the events in each quadrant. See Del Rio Pesado (1983) for such an account. Here we summarize those observations.

Much of the behavioral variability could be attributed to demographic variability. One demographic factor was the number of nests in each quadrant. The initial number of slave-maker nests in different quadrants ranged from 2 to 6 , while the initial number of 
host-species nests ranged from 0 to 17 . This variablity in nest density is probably correlated with small-scale differences in the availability and suitability of natural nest sites. In addition, the history of slavery in a particular spot might affect nest density, since $H$. americanus colonies may destroy or drive away adjacent host-species colonies.

Another kind of demographic variability involved the number of nests occupied by single colonies. Some $H$. americanus and some host-species colonies were initially polydomous. In the laboratory, some initially polydomous colonies moved into a single nest (became monodomous) before any significant interactions with members of other colonies occurred; but others remained polydomous during behavioral interactions with ants from other colonies (Del Rio Pesado \& Alloway 1983). To raid host-species nests successfully, $H$. americanus colonies must deploy raiding parties containing several $H$. americanus workers. In successful polydomous H. americanus colonies, the slaves made this possible by carrying all or almost all the parasite workers to a single nest before raiding began. While so doing, the slaves sometimes (but not always) moved the entire $H$. americanus colony into one nest. In other polydomous slave-maker colonies where the slaves failed to assemble the parasite workers in this way, many slave-makers were killed during uncoordinated attacks on target nests.

A third kind of demographic variability involved differing degrees of maturity among slave-maker colonies. When collected, some of our $\boldsymbol{H}$. americanus colonies were incipient (i.e. initially contained only an $\boldsymbol{H}$. americanus queen, some slaves, and a brood), while others already possessed slave-maker workers. Wesson (1939), studying ants from the east-central United States, found that $H$. americanus began to raid only after the overwintered $H$. americanus brood had matured. In contrast, overwintered parasite workers in our colonies from southern Ontario began to raid before all their overwintered brood had matured. As young $H$. americanus workers eclosed, they augmented the raiding forces of mature colonies and initiated raiding in incipient colonies. Thus, mature colonies could start raiding earlier and had the potential to raid longer than incipient colonies. In both incipient and mature colonies, first-year $H$. americanus workers were involved in all phases of raiding (i.e. scouting, attacking target nests, and transporting captured brood). 
In this last respect, $H$. americanus apparently differs from the European $H$. sublaevis (Nylander), in which slave-makers in mature colonies do not begin to scout until their second year (Buschinger et al. 1980). We also observed an apparent effect of experience on scouting. On their first forays in the spring or after eclosion, scouts ventured only a short distance from their nest. The distance travelled became greater as the number of forays increased.

Alloway (1979) observed that $H$. americanus workers could scout either singly or in small groups. In the present study, only individual scouting was observed. Alloway (1979) also observed that, whenever a lone scout discovered the entrance to a target nest, it would return to its own nest and recruit a raiding party. However, in the present study, lone scouts sometimes attacked target nests by themselves. Nevertheless, lone $H$. americanus workers rarely, if ever, captured any brood. Invasion of a target nest by a single slave-maker excited the target-colony workers and often caused them to attack the intruder. Some lone intruders were killed.

The success of raider recruitment was highly variable. Upon entering its nest, a scout that had discovered the entrance to a target nest was immediately surrounded by a cluster of slave-makers and slaves. Shortly thereafter, the scout would make its way back to the nest entrance and leave. That the slave-maker was now almost certainly laying down a pheromone trail was indicated by the fact that it conspicuously dragged its gaster along the substrate while being closely followed by a column of other slave-makers and/or slaves. All scouts that had located target nests excited their nestmates; and most initiated processions. The variable success of raider recruitment seemed to depend on the "steadiness" of the recruiter's movement and orientation while leading the procession. Successful recruiters moved steadily forward without making any abrupt turns. Less successful recruiters stopped for prolonged periods and changed direction abruptly. Such hesitation caused nestmates to leave the procession; and badly disoriented scouts lost all their followers. Some initially unsuccessful individuals later relocated the target nest and went back to their nest to try again.

The arrival of a raiding party containing several $H$. americanus workers and (often) a number of slaves always caused "alarm" in the target nest. Workers and queens would snatch up larvae and pupae and make frenzied efforts to leave the nest. Whenever they found a 
place where they could safely deposit any brood with which they had escaped, the workers returned to the invaded nest and carried off more brood. The slave-makers countered all these efforts by guarding the nest entrance (Alloway 1979) and by charging and snapping at target-nest workers.

Alloway (1979) observed that target-nest workers always fled with whatever brood they might manage to carry almost immediately after the arrival of a raiding party. In these circumstances, the slavemakers did not use their large, specialized mandibles against the residents of target nests. In the present study, a broader range of target-nest resistance and slave-maker aggression were observed. The workers in some target nests fled very shortly after the raiders arrived; and, in these cases, the slave-makers injured very few, if any, target-nest residents. However, in other target nests, the workers bit and stung the invaders. The slave-makers crushed such resistance by employing their large mandibles to dismember their adversaries. Slaves in raiding parties also attacked target-colony workers, but it was apparent that the success of the always outnumbered raiders depended mainly upon the activities of the slavemakers.

After all the adults had been killed or driven from the target nest, the raiders transported the captured brood to the slave-maker nest. Most brood was carried by slave-makers, although slaves sometimes carried one or two larvae or pupae. Brood transport generally lasted only a few hours, after which the raiding party vacated the target nest. Only one $H$. americanus colony manifested the phenomenon reported by Wesson (1939) of raiders requiring 2 or 3 days to complete brood transport. After the raiding party had abandoned the target nest, its previous inhabitants often returned.

\section{Other Behavior}

Our observations confirm that Leptothorax slaves do most of the work in $H$. americanus colonies. The slaves forage for food, feed and groom the parasite adults and brood, and defend the area around $H$. americanus colonies by attacking foraging workers from neighboring Leptothorax colonies whenever they are encountered near an $H$. americanus nest. The slave-makers do none of these things on a regular basis. Indeed, the parasites appear never to leave their nests except to scout (i.e. to "look for" target nests). Since scouting slave-makers invariably return to the same nest from which they departed, the parasites are even dependent on their slaves to 
move them from nest to nest in polydomous colonies. Nevertheless, H. americanus workers possess certain vestiges of non-parasitic behavior. Inside their nest, $H$. americanus workers routinely groom one another, periodically share regurgitated food with other slavemakers and slaves, and occasionally engage in what appears to be brood care. Parasite workers may even eat if they encounter food while scouting. On such occasions, one can infer that the slavemaker is scouting (and not foraging) from the fact that, after eating, it continues to "look for" a target nest, instead of returning directly to its own nest, regurgitating to nestmates, and recruiting them to the food source. H. americanus workers never recruit or follow nestmates except in the context of slave raids.

Although Leptothorax slaves generally look after the slavemakers, we observed many instances of slave aggression against slave-makers. In 9 slave-maker colonies, we saw slaves biting and dragging $H$. americanus workers out of slave-maker nests. A few $H$. americanus workers lost parts of appendages as a result of these attacks. However, we never saw a slave-maker attack a slave; and we never witnessed anything resembling a generalized "slave revolt". Individual $H$. americanus workers were attacked by individual slaves. The same slave which attacked one slave-maker would feed and groom another; and any slave-maker that was attacked by one slave was cared for by others.

A somewhat different kind of slave aggresssion was seen in one of our incipient $H$. americanus colonies. When collected, this colony possessed a single nest containing an $\mathrm{H}$. americanus queen, $17 \mathrm{~L}$. longispinosus workers, and a brood. Throughout the course of our observations, the slaves fed and groomed the parasite queen and tended her brood through the pupal instar. However, the slaves killed all eclosing $H$. americanus workers. Similar events have been observed in other incipient $H$. americanus colonies (R. J. Stuart, personal communication).

As we have noted, slaves ordinarily defend the area surrounding H. americanus nests against incursions by unenslaved Leptothorax workers. Similarly, unenslaved leptothorax workers defend areas around their nests against incursions by Leptothorax slaves. These phenomena, together with the fact that both enslaved and unenslaved Leptothorax workers fight for their respective colonies during slave raids, indicate that enslaved and unenslaved Leptothorax workers generally recognize one another as belonging to different 
colonies. However, these behavioral barriers between colonies are sometimes imperfect in the case of incipient slave-maker colonies. For example, let us consider the situation in Quadrant 3.

When collected, this quadrant contained two incipient $H$. americanus colonies, each of which was located near an apparently unparasitized $L$. longispinosus nest. In both cases, some of the slaves entered the nearest $L$. longispinosus nest without being attacked; and, reciprocally, some of the seemingly unenslaved $L$. longispinosus workers entered the $H$. americanus nest with impunity. On one occasion, a slave picked up the $H$. americanus queen in one of the parasite nests and carried her to the nearest L. longispinosus nest. The arrival of the parasite female caused all the adults in that nest to flee. Later the same day, a slave carried the H. americanus queen back to the nest from which she had come. Then, over a 12-day period, many of the workers which had originally fled moved in and began to live peacefully with the $H$. americanus queen in her nest.

Equally interesting events involved the other incipient parasite colony in the same quadrant. A slave which could peacefully enter the nearest $L$. longispinosus nest began to carry brood and workers from that nest into the $H$. americanus nest. Some of the in-coming L. longispinosus workers were accepted immediately by the other slaves, while others were initially attacked. However, after 15 days, all the workers from the unparasitized nest were living peacefully with the $H$. americanus queen. A few days later, several $L$. longispinosus workers killed the L. longispinosus queen which had been living in the unparasitized nest.

\section{Discussion}

Both Wesson (1939) and Alloway (1979) produced slave raids by selecting target nests and placing them in arenas with relatively populous, single-nest $H$. americanus colonies. The present study was the first in which a broader sample of $H$. americanus colonies has been observed and the first in which $H$. americanus colonies have been observed interacting with other colonies near which the slave-makers had been living in nature. These procedural differences probably account for the discrepencies between the behavioral events observed here and those described by Alloway (1979). Similar procedural differences, combined with possible regional differ- 
ences between populations, may account for differences between the present results and those of Wesson (1939).

A number of our observations pertain to limits on the success of slave-raiding in polydomous parasite colonies. Individual $H$. americanus workers can rarely capture brood and are sometimes killed by target-colony workers. Yet, groups of 4 or 5 H. americanus workers can successfully raid almost any target nest. Thus, $H$. americanus colonies need to deploy their raiders in raiding parties containing several parasite workers. However, polydomy sometimes prevents such deployment. The slave-makers rely on their slaves to carry them from nest to nest in polydomous colonies; and the slaves often fail to assemble the slave-makers in a single nest from which successful raids could be mounted. As a consequence, some polydomous $H$. americanus colonies fail to organize raiding parties containing enough slave-makers to capture brood from neighboring hostspecies colonies.

This difficulty encountered by $H$. americanus colonies living in more than one nest has led us to question the adaptive value of polydomy in the slave-maker population studied. Both the Leptothorax host species enslaved by $H$. americanus in the Toronto region form facultatively polydomous colonies (Alloway et al. 1982). Thus, if enslaved host-species workers behave like unenslaved conspecifics, slaves should tend to provide a polydomous colony structure for the parasites. Perhaps, some $H$. americanus colonies are pulydomous because of this behavioral propensity of their slaves and despite the fact that polydomy is detrimental to efficient raiding.

In addition, polydomy may account for some of the overt aggression observed in the present study. By extension, polydomy might partly explain the similar forms of slave aggression manifested by Leptothorax slaves living in L. duloticus colonies (Wilson 1975).

Let us imagine that a slave-maker colony divides, with some of the parasites and slaves remaining in the original nest, while others move to another nest. Let us further suppose that the slave-makers in the two nest raid independently. In such a situation, young slaves maturing from captured brood in each nest might learn to recognize as nestmates only those particular slave-makers with which they were living. If the ants from the two nests later reunited, then the old slaves might accept all the slave-makers, while the young slaves 
accepted only familiar individuals. This scenario could explain our observations of slaves biting and dragging slave-makers out of nests. The aggression observed was always an individual matter. Some slaves accepted all the slave-makers, while other slaves accepted certain slave-makers and attacked others.

A somewhat similar hypothesis might account for the imperfect behavioral boundaries between some incipient $\boldsymbol{H}$. americanus colonies and nearby unparasitized nests. An $\boldsymbol{H}$. americanus queen founds a new colony by entering a host-species nest, killing or driving off the adults, and capturing worker pupae that subsequently mature to become her first slaves (Wesson 1939; Sturtevant 1927). If a parasite queen founded a colony in one nest of a polydomous Leptothorax colony, it would not be surprising if some of the parasite's first slaves were acceptable in other nests of the same colony. Similarly, "free" workers from that colony might be acceptable in the slavemaker nest. However, this hypothesis cannot explain how, under these circumstances, a parasitized nest could unidirectionally siphon brood and workers from an unparasitized nest or how an $H$. americanus queen could become more attractive than a Leptothorax queen. Yet, $H$. americanus queens and the queens of many other socially parasitic species somehow usurp the place of host-species queens (Wilson 1971). How parasite queens accomplish this feat remains an important subject for future research.

Polydomy also cannot account for the case where slaves cared for an $H$. americanus queen and her brood but killed all eclosing $H$. americanus workers. Explaining this phenomenon would require understanding the mechanisms of nestmate recognition in these species; and these mechanisms are incompletely understood. However, studies in progress (R.J. Stuart, personal communication) indicate that apparent "mistakes" in nestmate recognition are possible in these host species and that $H$. americanus may exploit these possibilities. When slaves work for a parasite queen, they may be mistakenly identifying her as a nestmate. When the same slaves destroy the parasite's offspring, they may be correctly identifying them as aliens.

Gladstone (1981) discussed various theoretical reasons why slave workers should not "revolt" against slave-makers. However, our observations of $H$. americanus colonies and Wilson's (1975) observations of Leptothorax duloticus colonies show that individual slaves sometimes manifest what might be interpreted as "rebellious behavior". If our inferences about polydomy are correct, whole 
slave worker forces may even organize slave-maker colonies in a way which produces inefficient raiding. Nevertheless, we doubt that any of these behavioral phenomena are manifestations of evolved host-species defenses against slave-makers. We suppose that the behavior of host-species workers has evolved to maximize the reproductive potential of host-species queens. Slave-maker populations are so sparse that only a small proportion of host-species colonies are ever raided. Thus, slavery seems unlikely to exert significant selection pressure on host-species populations; and we believe that the facultative polydomy and polygyny found in these hostspecies are adaptations to conditions in host-species (not parasite) colonies.

In these host species, polygyny involves the acceptance of newly mated young queens in existing colonies. Simultaneously, polydomy involves a more or less continual exchange of workers, queens, and brood among nests; and such commerce requires workers in one nest to accept workers, queens, and brood from other nests of the same colony (Alloway et al. 1982). An incidental effect of these characterstics of host-species colonies is to produce a worker caste which is vulnerable to enslavement. Of course, a second effect of polydomy is to produce a worker caste which tends to organize multiple-nest colonies; and life in multiple nests may be disadvantageous to slave-makers. In other words, Harpagoxenus americanus parasitizes the labor of workers which possess a "mixed bag" of behavioral characteristics. Some of these characteristics may facilitate enslavement, while others may produce inefficient slave-maker colonies. However, the assertion that host-species workers have evolved to be inefficient slaves seems only a little more likely than the assertion that they have evolved to be slaves at all.

\section{Summary}

Colonies of the slave-making ant, Harpagoxenus americanus (Emery), and two of its host species (Leptothorax ambiguus Emery and L. longispinosus Roger) were observed under "seminatural" conditions, in which the ants lived in artificial nests arranged to reconstruct the spatial relationships among their natural nests. Some of the slave-maker and host-species colonies were polydomous. In some polydomous slave-maker colonies, the slaves carried all the $H$. americanus workers into one nest before the onset of raiding. When thus assembled, the slave-makers efficiently captured 
brood from nearby host-species colonies. In other polydomous colonies where the slave-makers remained in more than one nest, the parasites conducted unco-ordinated raids and incurred many casualties. Several kinds of slave aggression against the slave-makers are described. However, slaves "peacefully" augmented the slave worker forces of some incipient $H$. americanus colonies.

\section{REFERENCES}

Alloway, T. M.

1979. Raiding behaviour of two species of slave-making ants, Harpagoxenus americanus (Emery) and Leptothorax duloticus Wesson. Animal Behaviour 27: 202-210.

Alloway, T. M., A Buschinger, M. Talbot, R. Stuart, \& C. Thomas.

1982. Polygyny and polydomy in three North American species of the ant genus Leptothorax Mayer (Hymenoptera: Formicidae). Ps.j'che 89: 249-274.

Buschinger, A., \& T. M. Alloway.

1977. Population structure and polymorphism in the slave-making ant Harpagoxenus americanus (Emery). Psyche 83: 233-242.

Buschinger, A., W. Ehrhard, AND U. Winter.

1980. The organization of slave-raids in dulotic ants: A comparative study (Hymenoptera: Formicidae). Zeithschrift fur Tierpsy'chologie 53: 245-264.

Del Rio Pesado, M. G..

1983. Polydomy in the slave-making ant, Harpagoxenus americanus (Emery) (Hymenoptera; Formicidae). M.Sc. Thesis, University of Toronto.

Del Rio Pesado, M. G. \& T. M. Alloway.

1983. Polydomy in the slave-making ant, Harpagoxenus americanus (Emery) (Hymenoptera: Formicidae). Psyche 90: 151-162.

Gladstone, D. E.

1981. Why there are no ant slave rebellions. American Naturalist 117: 779-781. Sturtevant, A. H.

1927. The social parasitism of the ant Harpagoxenus americanus. Psyche 34: $1-9$.

WESSON, L. G., JR.

1939. Contribution to the natural history of Harpagoxenus americanus Emery (Hymenoptera: Formicidae). Transactions of the American Entomolgical Society' 65: 97-122.

WILSON, E. O.

1971. The Insect Societies. (Cambridge, Mass.,: Belknap Press of Harvard University Press, $\mathrm{x}+548 \mathrm{pp}$.)

1975. Leptothorax duloticus and the beginnings of slavery in ants. Evolution 29: $108-119$. 

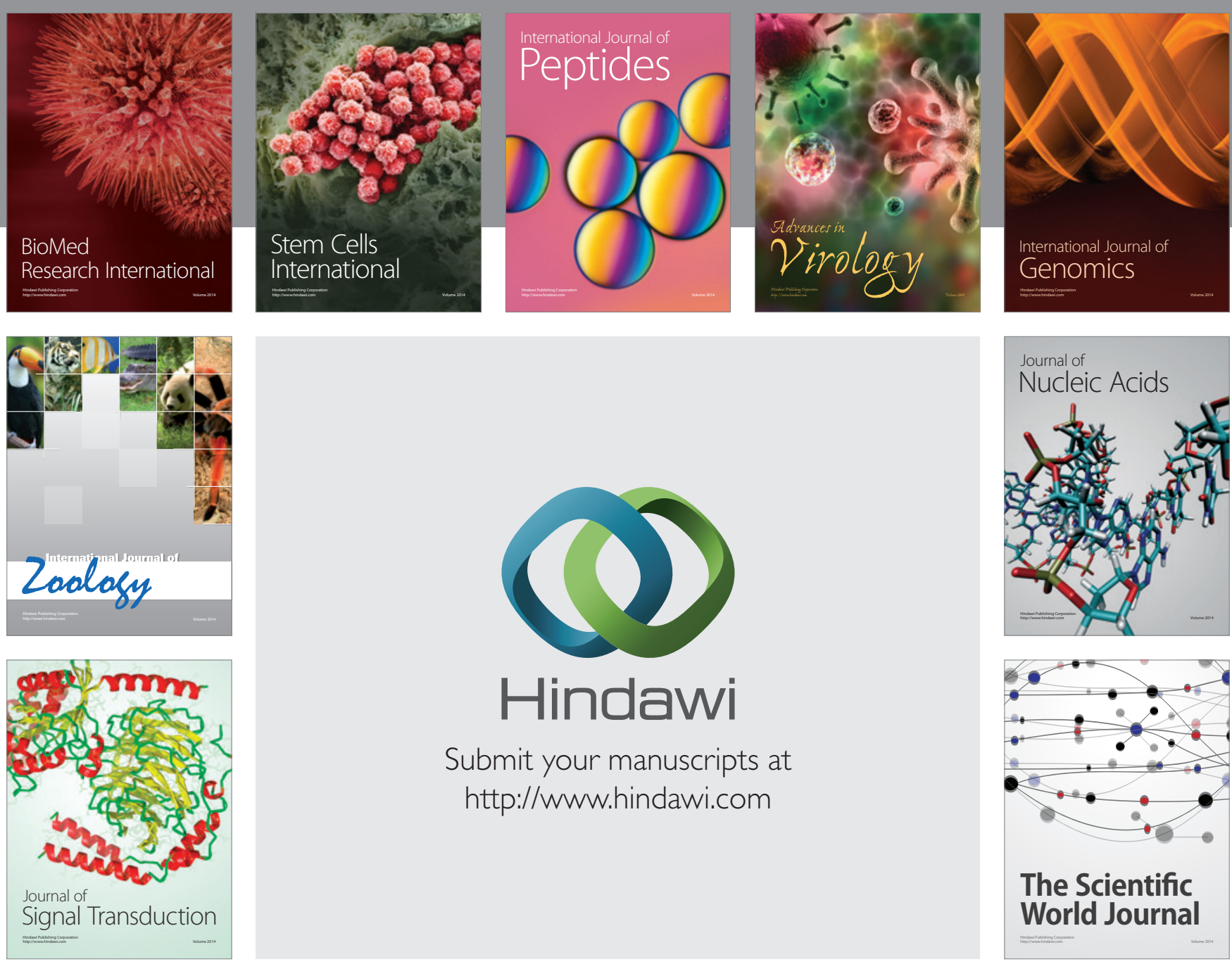

Submit your manuscripts at

http://www.hindawi.com
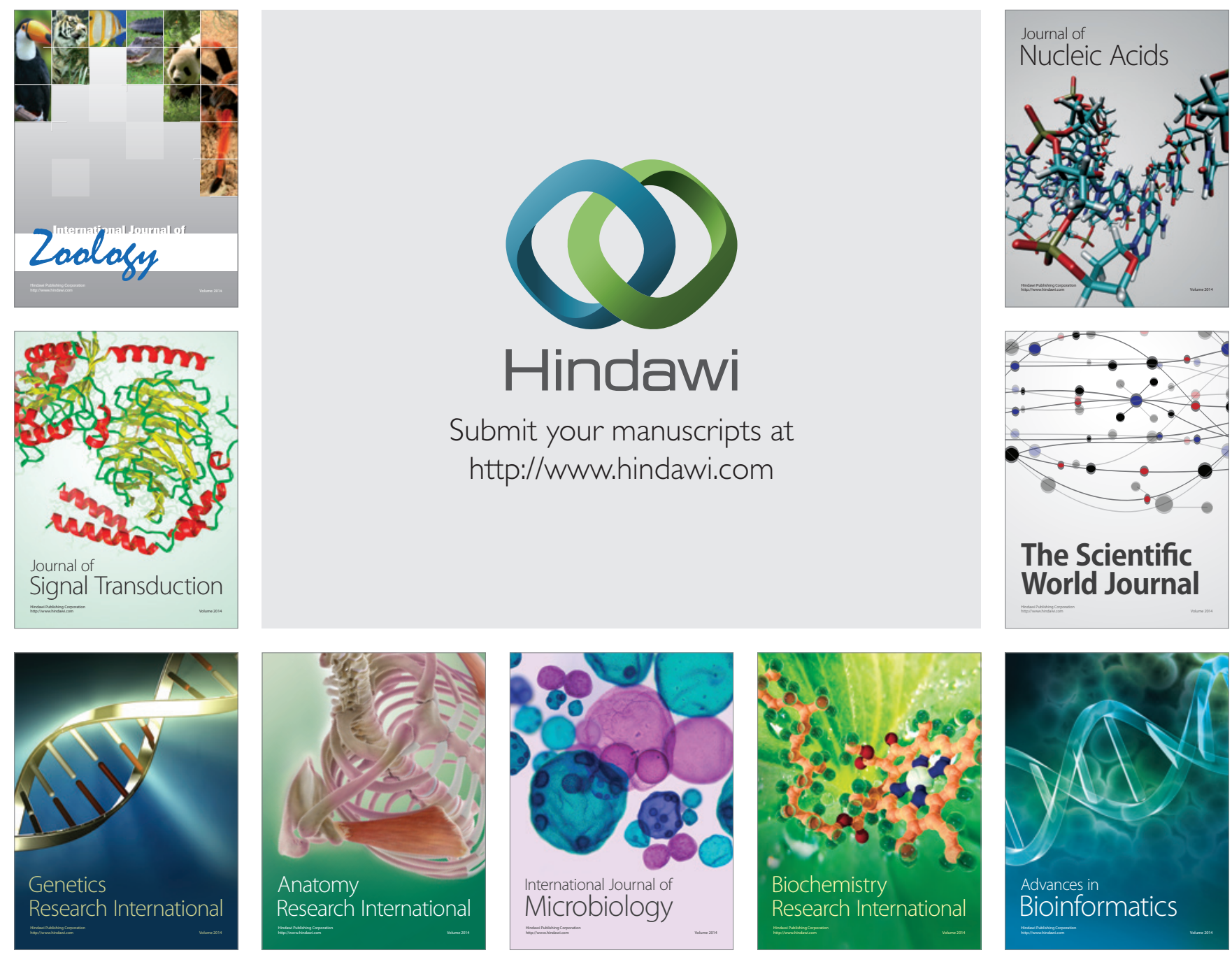

The Scientific World Journal
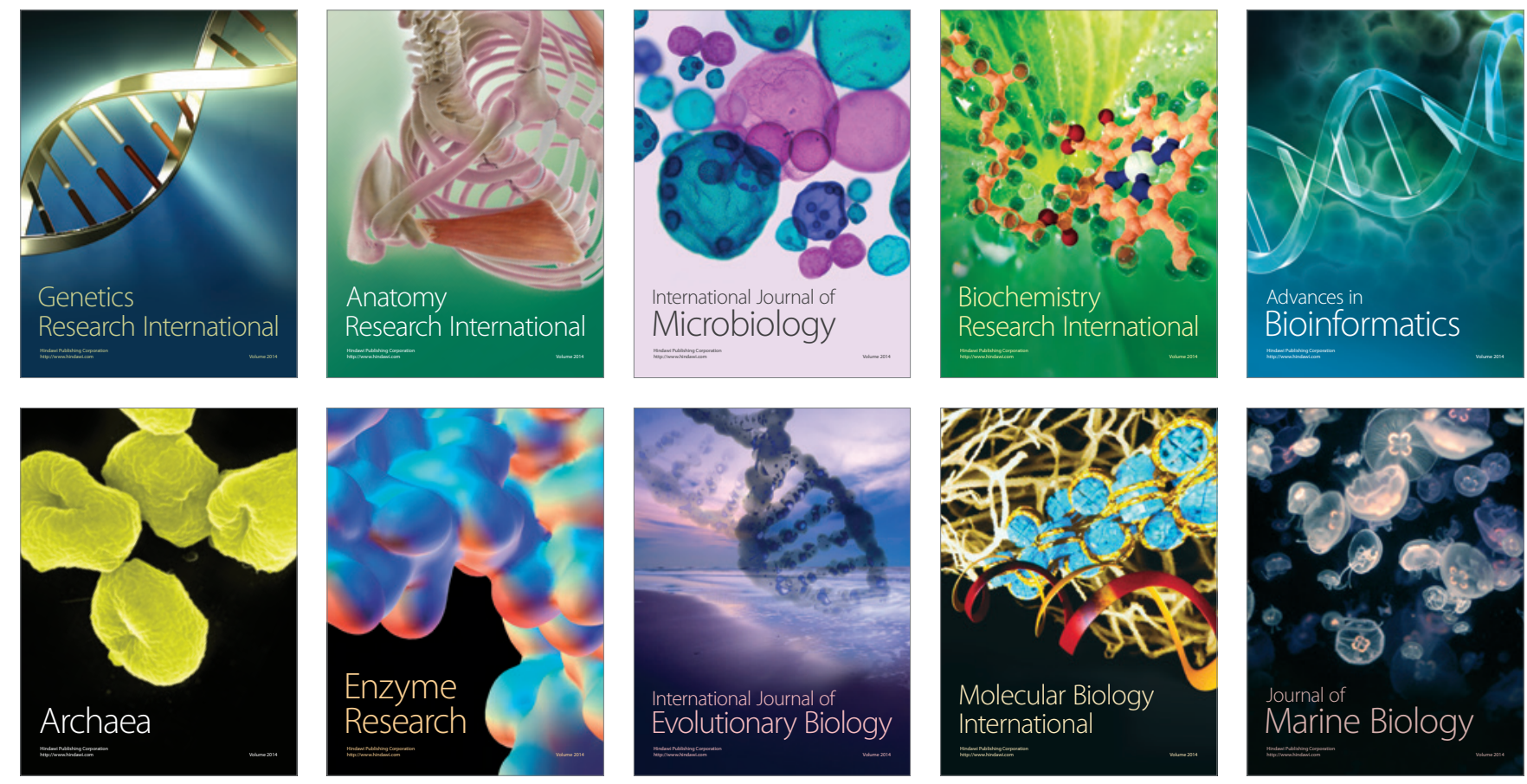